\title{
Socio-economic inequalities in physical functioning: a comparative study of English and Greek elderly men
}

\author{
FAIZA TABASSUM*, GEORGIA VERROPOULOU† \\ CLEON TSIMBOS $†$, EDLIRA GJONGA* \\ and ELIZABETH BREEZE*
}

\begin{abstract}
The associations between socio-economic position (SEP) and physical functioning have frequently been investigated but little is known about which measures of SEP are the best to use for older people. This study examined how different SEP indicators related to the physical functioning of men aged $5^{\circ}$ or more years in England and Greece. The data derived from Wave I of the English Longitudinal Study of Ageing (ELSA) and from the Survey of Health, Ageing and Retirement in Europe (SHARE). Self-reported physical functioning limitations and mobility difficulties were combined and categorised into 'no disability', 'mild disability' and 'severe disability'. The SEP indicators studied were: wealth, educational level and occupational class. The findings indicate that respondents with less wealth, fewer educational qualifications and lower occupational class were more likely to experience mild or severe physical disability than those of high SEP. When all three measures of SEP were adjusted for each other, in both samples wealth maintained a strong association with mild and severe disability, while education was associated with severe disability but only among English men. Occupational class was not strongly associated with physical disability in either case. Hence, among English and Greek older men, wealth was a more important predictor of physical functioning difficulties than either occupational class or education.
\end{abstract}

KEY WORDS - physical functioning, older people, wealth, education, occupational class, men, England, Greece.

* Epidemiology and Public Health, University College London, London, UK.

$\dagger$ Department of Statistics and Insurance Science, University of Piraeus, Athens, Greece.

$\$$ Centre for Longitudinal Studies, Institute of Education, University of London, London, UK. 


\section{Introduction}

Limitations in physical functioning are associated with a lower quality of life (Blane, Netuveli and Montgomery 2008), reduced participation in society (Wilkie et al. 2007), chronic disease and mortality (Bhattacharya, Choudhry and Lakdawalla 2008; Lamarca et al. 2003; Launer et al. 1994; Scott et al. 1997). Measures of the Activities of Daily Living (ADLs), the Instrumental Activities of Daily Living (IADLs) and mobility problems have customarily been used to measure dependency or disability. ${ }^{1}$ While the associations between physical functioning and socio-economic position (SEP), measured as wealth, educational qualifications or occupational status, have been investigated, this has been undertaken less often for older people than for those of working age (Berkman and Gurland 1998; Coppin et al. 2006; Ebrahim et al. 2004; Minkler, Fuller-Thomson and Guralnik 2006; von dem Knesebeck, Verde and Dragano 2006; Winkleby et al. I992; Zimmer and House 2003). It has been suggested that SEP predicts physical functioning difficulties independently of lifestyle and demographic factors (Ebrahim et al. 2004). Previous research has indicated the importance of using multiple measures of SEP in older age (Berkman and Gurland I998; Hyde and Jones 2007) but it is still unclear which measures best reflect variations in health among older people (Artazcoz and Rueda 2007; Grundy and Holt 200I). Most studies have used income rather than wealth as a SEP indicator, but there may be less variation in income among those who are predominantly pensioners, and it seems likely that the value and security of the wealth that they have accumulated over their life course is a more important variable (Costa-Font 2008; Keister and Moller 2000). A gradient in disability with wealth has been shown (Freedman et al. 2008), and other studies have shown variations in health by educational attainment and social class (Huisman, Kunst and Mackenbach 2003; Jagger et al. 2007; von dem Knesebeck et al. 2006; Winkleby et al. 1992; Zimmer and House 2003).

While health differentials between European countries have been reported (Olsen and Dahl 2007) as well as socio-economic inequalities in health within countries (Eikemo et al. 2008; Huisman, Kunst and Mackenbach 2003; Mackenbach and Bakker 2003; Mackenbach and Kunst 1997), there have been no comparisons between England and Greece. This paper presents an assessment of the relative importance of various measures of SEP on different levels of disability in old age for Greek and English men using data from the English Longitudinal Study of Ageing (ELSA) and the Survey of Health, Ageing and Retirement in Europe (SHARE). Understanding any differences between these two countries would throw light on whether, when designing policies to reduce health 
inequalities, it is correct to assume that socio-economic inequalities across western and southern Europe are homogeneous. Previous studies have suggested that particular measures of SEP might not apply equally to various European populations (Huisman, Kunst and Mackenbach 2003; Jurges 2007; Mackenbach et al. 1997). Pronounced differences between Greece and England in socio-economic indicators of health status have been reported (Olsen and Dahl 2007). England has greater per capita public social expenditure on health and a higher gross domestic product (GDP), while its Gini coefficient of income inequality is more favourable (Olsen and Dahl 2007; United Nations Development Programme 2006). Given these differences in their basic economic indicators, it is of interest to explore whether inequalities in health among older people in the two countries are uniform. The main objective of our study was to investigate which of three measures of SEP - wealth, educational attainment and occupational class-had stronger effects on physical disability. The analysis also examined whether the associations are stronger for mild or severe disability.

\section{Methods and materials}

\section{The data}

The data for this study are from Wave I of both ELSA and SHARE (release two). The ELSA Wave I sample, excluding proxies and young partners of core members, comprised II,392 men and women aged 50 or more years in March 2002 who were living in private households in England. The present analysis was confined to the 5,187 men. Of these, I43 (3\%) were omitted because of missing information for the variables of interest, so the analysis sample was $5,044 .^{2}$ The design of SHARE was based on the United States Health and Retirement Survey and ELSA. ${ }^{3}$ The baseline survey was conducted in 2004 in 12 European countries, with the target population being people aged 50 or more years and their spouses but excluding the institutional population. In total, 2,67i persons were interviewed excluding any spouse aged less than 50 years. The Greek sample had I,239 men, I98 (I6\% of the SHARE sample) of whom had missing information on occupational status and were omitted from the analysis, leaving an analysis sample of I,04I men.

\section{Measures of disability}

In ELSA and SHARE, information about physical functioning was collected by means of self-report questions during the computer-assisted 


\section{T A B L E I. Items used to create the disability scale}

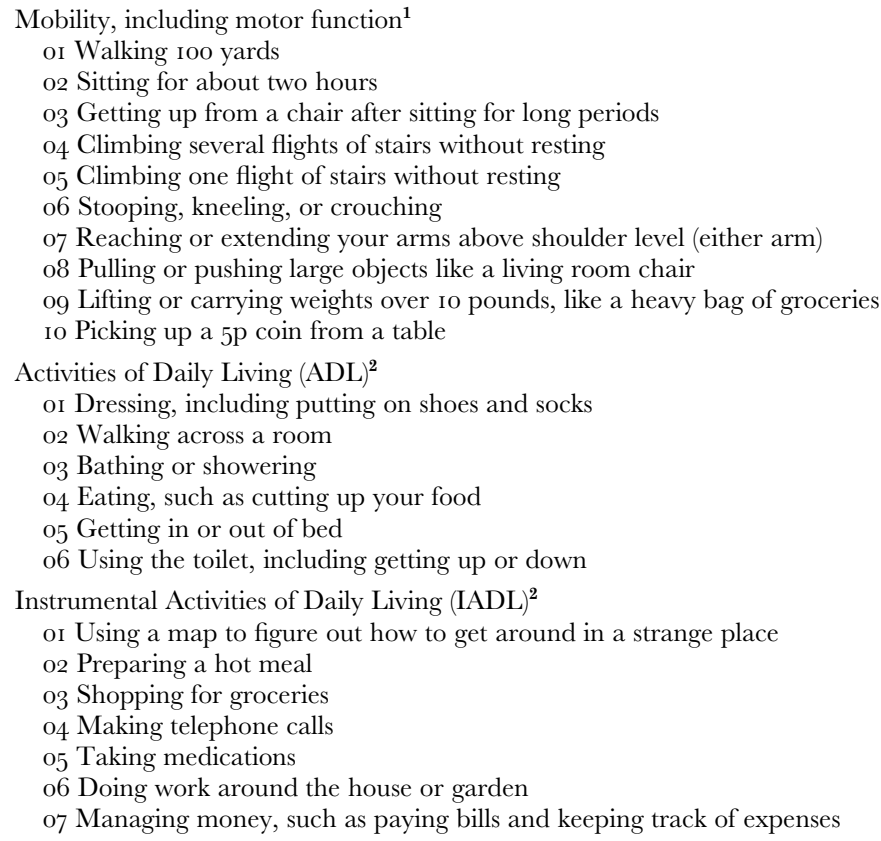

Notes: I. Because of a physical or health problem, do you have difficulty doing any of the activities on this card? Exclude any difficulties that you expect to last less than three months. 2. Here are a few more everyday activities. Please tell me if you have any difficulty with these because of a physical, mental, emotional or memory problem. Again exclude any difficulties you expect to last less than three months.

personal interview. The core questions about physical functioning had three domains: the ADLs or bodily care, the IADLs or the activities necessary for independent living in a community, and mobility difficulties (motor skills, stamina and strength in both lower and upper limbs). These scales were simplified from the items proposed by Katz et al. (I963) and Lawton and Brody (I969), and the question items are very similar to those used in the Health and Retirement Survey (Fonda and Herzog 2004). There were ro mobility items, six ADLs and seven IADLs (see Table I). For all three measures of disability, the respondents were asked to report the presence of difficulties arising from health problems. For the number of reported functional limitations a summated score for the 23 binary variables corresponding to ADLs, IADLs and mobility was constructed. The internal consistency as estimated by Cronbach's alpha was 0.9I for the English and 0.85 for the Greek data, thus allowing use of the aggregate 
measure. Finally, the disability variable was sub-divided into three categories: no disability (o difficulties), mild disability ( $\mathrm{I}-6$ difficulties) and severe disability (7-23 difficulties).

\section{Socio-economic position variables}

We used three measures of SEP: wealth, educational level and occupational class. All the SEP measures refer to status at Wave I of ELSA and of SHARE. In ELSA, wealth was calculated by colleagues at the Institute of Fiscal Studies (Banks et al. 2006; Banks, Emmerson and Tetlow 2005), and in SHARE, wealth is based both on reported and imputed values calculated by the central SHARE team (Börsch-Supan and Jürges 2005). In both ELSA and SHARE, wealth is calculated as the sum of many items, including the values of property and physical assets, mortgages, bank deposits, stock holdings, bonds, mutual funds, life insurance policies and individual retirement accounts. For this analysis, wealth was divided into tertiles for the all-age sample.

Both in ELSA and SHARE, educational level was defined according to the highest qualification attained; in SHARE the codes are according to the International Standard Classification of Education 1997 (ISCED-97; United Nations Educational, Scientific and Cultural Organization 2006). Educational attainment had three categories: low (basic/primary/foreign education), middle (up to secondary education equivalent to the United Kingdom (UK) Advanced Level General Certificate of Education) and high (higher education including vocational qualification below degree level).

The ELSA respondents (including the permanently sick or disabled and the unemployed) were assigned occupational categories according to the National Statistics Socio-economic Classification (NS-SEG; Office of National Statistics 2005) on the basis of their most recent occupation. A similar classification of occupations for the SHARE respondents used the International Standard Classification of Occupations (ISCO-88; Elias and Birch i994). Women were excluded from the present analysis as a high proportion could not be assigned an occupational code (about 50\% of the Greek SHARE sample). Finally, in both ELSA and SHARE the respondents were allocated into the following occupational groups: (I) managerial and professional, (2) intermediate occupations, and (3) routine and manual occupations.

\section{Statistical methods}

The main objective of the paper was to examine whether the association between socio-economic factors and both severe and mild physical 
T A B L E 2. Respondents' characteristics in England and Greece

\begin{tabular}{|c|c|c|c|c|}
\hline \multirow[b]{2}{*}{ Variable and category } & \multicolumn{2}{|c|}{ England 2002} & \multicolumn{2}{|c|}{ Greece 2004} \\
\hline & Frequencies & $\%$ & Frequencies & $\%$ \\
\hline \multicolumn{5}{|l|}{ Disability: } \\
\hline None & 2,412 & 47.8 & 575 & $55 \cdot 3$ \\
\hline Mild & I,936 & $3^{8.4}$ & $4 \mathrm{I} 3$ & 39.6 \\
\hline Severe & 696 & $\mathrm{I} 3.8$ & 53 & $5 \cdot 1$ \\
\hline \multicolumn{5}{|l|}{ Wealth: } \\
\hline Highest tertile & I,908 & 37.8 & 415 & 39.9 \\
\hline Middle tertile & I,749 & $34 \cdot 7$ & 345 & $33 . \mathrm{I}$ \\
\hline Lowest tertile & I, 387 & 27.5 & $28 \mathrm{I}$ & 27.0 \\
\hline \multicolumn{5}{|l|}{ Educational attainment: } \\
\hline High & I,397 & 27.7 & 218 & 20.9 \\
\hline Middle & $\mathrm{I}, 79 \mathrm{I}$ & $35 \cdot 5$ & 368 & $35 \cdot 4$ \\
\hline Low & 1,856 & 36.8 & 455 & 43.7 \\
\hline \multicolumn{5}{|l|}{ Occupational class: } \\
\hline Managerial and professional & $\mathrm{I}, 83 \mathrm{I}$ & 36.3 & 333 & 32.0 \\
\hline Intermediate & 953 & I8.9 & I82 & I 7.5 \\
\hline Routine or manual & 2,260 & 44.8 & 526 & 50.5 \\
\hline Mean age (standard deviation) & $64.8(9.9)$ & & $64.0($ I0.2) & \\
\hline Sample size & 5,044 & & I,O4I & \\
\hline
\end{tabular}

disability differed between English and Greek men. Multinomial logistic regression was used as the outcome variable has more than two categories (Agresti 2002). ${ }^{4}$ All the analyses were carried out separately for English and for Greek men. The following four models of the associations of disability were constructed and all were adjusted for age: (a) with wealth, (b) with education, (c) with occupational class, and (d) with wealth, education and occupational class, simultaneously adjusted for each other. The reference category was 'no physical disability' in all the models. Finally, we calculated the predicted probabilities of no physical disability, mild physical disability and severe physical disability for the final model.

\section{Results}

\section{Characteristics of the ELSA and SHARE respondents}

Table 2 shows the basic characteristics of the two samples. The ELSA sample has 5,044 men while the SHARE sample has I,04I men. The average ages are 64.8 years for the English men and 64.0 years for the Greeks. Around one-half of both samples reported no disability $(48 \%$ of the English and $55 \%$ of the Greeks), while more English than Greek men reported severe physical disability ( $14 \%$ versus $5 \%$ ). The wealth 
T A в L E 3. Associations between disability and measures of socio-economic position at Waves I of ELSA and SHARE

\begin{tabular}{|c|c|c|c|c|c|c|}
\hline \multirow[b]{3}{*}{$\begin{array}{l}\text { Socio-economic } \\
\text { position }\end{array}$} & \multicolumn{3}{|c|}{ England: level of disability } & \multicolumn{3}{|c|}{ Greece: level of disability } \\
\hline & None & Mild & Severe & None & Mild & Severe \\
\hline & $\begin{array}{c}\text { Number } \\
(\%)\end{array}$ & $\begin{array}{c}\text { Number } \\
(\%)\end{array}$ & $\begin{array}{c}\text { Number } \\
(\%)\end{array}$ & $\begin{array}{c}\text { Number } \\
(\%)\end{array}$ & $\begin{array}{l}\text { Number } \\
(\%)\end{array}$ & $\begin{array}{c}\text { Number } \\
(\%)\end{array}$ \\
\hline \multicolumn{7}{|l|}{ Wealth: } \\
\hline Highest tertile & $437(6 \mathrm{I} .8)$ & $645(33.8)$ & $84(4 \cdot 4)$ & 266 (64.I) & I $45(34.9)$ & $4($ I.O) \\
\hline Middle tertile & $796(45 \cdot 5)$ & $717(4 \mathrm{I} .0)$ & $236(13.5)$ & I88 (54.5) & I39 (40.3) & I8 (5.2) \\
\hline Lowest tertile & $437(3 \mathrm{I} \cdot 5)$ & $574(4 \mathrm{I} \cdot 4)$ & $376(27 . \mathrm{I})$ & I2I $(43 \cdot I)$ & I29 (45.9) & 3I (II.O) \\
\hline \multicolumn{7}{|l|}{ Education level: } \\
\hline High & $829(59 \cdot 3)$ & $497(35.6)$ & 7I $(5 \cdot I)$ & $\mathrm{I} 42(65 . \mathrm{I})$ & $70(32 . I)$ & $6(2.7)$ \\
\hline Middle & $892(49.8)$ & $682(38.1)$ & 217 (I2.I) & $224(60.9)$ & I34 (36.4) & Io $(2.7)$ \\
\hline Low & $69 \mathrm{I}(37.2)$ & $757(40.8)$ & $408(22.0)$ & $209(45 \cdot 9)$ & $209(45 \cdot 9)$ & $37(8.2)$ \\
\hline \multicolumn{7}{|l|}{ Occupational class: } \\
\hline $\begin{array}{c}\text { Managerial and } \\
\text { professional }\end{array}$ & I,024 (55.9) & $668\left(3^{6.5}\right)$ & I39 (7.6) & $20 \mathrm{I}(6 \mathrm{o} .4)$ & I24 (37.2) & $8(2.4)$ \\
\hline Intermediate & $477(50.0)$ & $35^{8}(37.6)$ & II 8 (I2.4) & I Iо $(60.4)$ & $69(37.9)$ & $3(\mathrm{I} .7)$ \\
\hline Routine and manual & 9II $(40.3)$ & $9 \operatorname{Io}(40.3)$ & 439 (I9.4) & $264(50.2)$ & $220(4 \mathrm{I} .8)$ & $4^{2}(8.0)$ \\
\hline
\end{tabular}

Notes: Each cell presents the frequency, with the row percentage in brackets (for the country). The sample size for the English Longitudinal Study of Ageing (ELSA) was 5,044, and for the Survey of Health, Ageing and Retirement in Europe (SHARE) I,04I. The chi-squared statistics for all the associations between level of disability and the socio-economic position measures were significant at $p<$ o.or.

distribution was similar in the two samples: there were more men in the highest wealth tertile than the lowest. Greek men had on average fewer educational qualifications than the English. For example, while 28 per cent of English men had a 'high' level of education, the comparable figure for Greek men was 2I per cent. In both samples, there were more men in the routine and manual occupations than in managerial occupations.

\section{Physical disability and socio-economic position}

Table 3 shows the associations between the different levels of physical functioning and the three measures of SEP. In both the ELSA and SHARE samples, the prevalence of severe physical disability increased with decreasing wealth $(p<$ o.oI $)$, education $(p<$ o.oI $)$ and occupational class $(p<$ o.or $)$. Conversely, the prevalence of reporting no physical disability decreased with less wealth $(p<$ o.oI $)$, education $(p<$ o.or $)$ and occupational status $(p<$ o.or). The sample sizes are small for certain subgroups of the Greek respondents, particularly for people with severe disability and high SEP, so the results should be interpreted with caution. 
T A B L E 4. Age-adjusted associations of mild and severe disability with socio-economic position factors among English and Greek older men

\begin{tabular}{|c|c|c|c|c|c|c|c|c|}
\hline \multirow[b]{2}{*}{ Outcome and predictors } & \multicolumn{4}{|c|}{ English sample } & \multicolumn{4}{|c|}{ Greek sample } \\
\hline & OR & $95 \%$ CI & OR & $95 \% \mathrm{CI}$ & OR & $95 \% \mathrm{CI}$ & OR & $95 \%$ CI \\
\hline \multicolumn{9}{|l|}{$\begin{array}{l}\text { Mild disability } \\
\text { versus no disability: }\end{array}$} \\
\hline Wealth: & \multicolumn{2}{|c|}{ Model I } & \multicolumn{2}{|c|}{ Model $_{4}$} & \multicolumn{2}{|c|}{ Model I } & \multicolumn{2}{|c|}{ Model $_{4}$} \\
\hline Highest tertile & I.OO & & I.OO & & I.OO & & I.0O & \\
\hline Middle tertile & I. $46^{* *}$ & I. $26-$ I. 68 & I. $3^{6 * *}$ & I.I $6-1.5^{8}$ & $\mathrm{I} .2 \mathrm{I}$ & o.88-I.65 & I.I9 & о.87-1.64 \\
\hline Lowest tertile & I. $8 \mathrm{I}^{* *}$ & I. $54^{-2.14}$ & I. $62^{* * *}$ & I. $35^{-\mathrm{I}} .9^{6}$ & I. $55^{* *}$ & I.II-2.17 & I. $53^{* *}$ & I.08-2.17 \\
\hline Education level: & \multicolumn{2}{|c|}{ Model 2} & \multicolumn{6}{|c|}{ Model 2} \\
\hline High & I.OO & & 1.00 & & I.OO & & I.OO & \\
\hline Middle & I.1. $7^{*}$ & I.OI-I. 37 & I.OI & $0.85^{-1.19}$ & I.09 & $0.7^{6}-\mathrm{I} .5^{8}$ & I.IO & $0.75^{-\mathrm{I} .6 \mathrm{I}}$ \\
\hline Low & I. $42^{* *}$ & I. $22-1.67$ & I.08 & $0.89^{-\mathrm{I} .29}$ & I. 25 & $0.86-\mathrm{I} .8 \mathrm{I}$ & I.I9 & $0.78-\mathrm{I} .82$ \\
\hline Occupational class: & \multicolumn{2}{|c|}{ Model $_{3}$} & \multicolumn{6}{|c|}{ Model $_{3}$} \\
\hline $\begin{array}{l}\text { Managerial and } \\
\text { professional }\end{array}$ & I.OO & & I.OO & & I.OO & & I.OO & \\
\hline Intermediate & I.I7 & $0.9^{8-\mathrm{I}} .39$ & I.04 & $0.86-\mathrm{I} .24$ & 0.96 & $0.64^{-\mathrm{I} .4 \mathrm{I}}$ & 0.92 & $0.62-\mathrm{I} .37$ \\
\hline Routine and manual & I. $47^{* * *}$ & I.28-1.69 & I. 18 & $0.99^{-\mathrm{I}} \cdot 39$ & I.07 & $0.79^{-\mathrm{I} .45}$ & 0.92 & $0.65^{-1.29}$ \\
\hline \multicolumn{9}{|l|}{$\begin{array}{l}\text { Severe disability } \\
\text { versus no disability: }\end{array}$} \\
\hline Wealth: & \multicolumn{2}{|c|}{ Model I } & \multicolumn{2}{|c|}{ Model 4} & \multicolumn{2}{|c|}{ Model I } & \multicolumn{2}{|c|}{ Model 4} \\
\hline Highest tertile & I.OO & & & & I.OO & & I.OO & \\
\hline Middle tertile & $3 \cdot 67^{* *}$ & $2.8 \mathrm{I}-4.79$ & $2.77^{* *}$ & $2.09-3.68$ & $5 \cdot 30^{* * * *}$ & г.68-16.70 & $4.68^{* * * *}$ & I. $46-\mathrm{I} 4.99$ \\
\hline Lowest tertile & $9 \cdot 04^{* *}$ & $6.9^{2-I I .8 I}$ & $5.86^{* * *}$ & $4 \cdot 3^{6-7.89}$ & 8. $13^{* * * *}$ & $2.65^{-24.9 I}$ & $6.68 * * *$ & $2.13^{-20.96}$ \\
\hline Education level: & \multicolumn{2}{|c|}{ Model 2} & \multicolumn{6}{|c|}{ Model 2} \\
\hline High & I.OO & & I.OO & & I.OO & & I.OO & \\
\hline Middle & $2.57^{* *}$ & I. $93-3.43$ & I. $57^{* *}$ & I.I6-2.I4 & $3 \cdot 43$ & $0.4 \mathrm{I}^{-28.47}$ & $3.2 \mathrm{I}$ & $0.35^{-28.72}$ \\
\hline Low & $5 \cdot 16^{* * *}$ & $3.9 \mathrm{I}-6.8 \mathrm{o}$ & $2.25 * *$ & เ. $64-3.08$ & $6.5^{2}$ & $0.85-50.07$ & 3.79 & $0.44^{-}-32.73$ \\
\hline Occupational class: & \multicolumn{2}{|c|}{ Model $_{3}$} & \multicolumn{6}{|c|}{ Model $_{3}$} \\
\hline $\begin{array}{c}\text { Managerial and } \\
\text { professional }\end{array}$ & I.OO & & 1.00 & & I.OO & & I.OO & \\
\hline Intermediate & I. $88 * *$ & I. $43^{-2.47}$ & I.o6 & $0.79^{-\mathrm{I} .4^{2}}$ & $0.5^{\mathrm{I}}$ & $0.12-2.13$ & 0.45 & O.IO-I.99 \\
\hline Routine and manual & $3 \cdot 40^{* *}$ & $2.74-4.22$ & I. $3^{*}$ & І.02-I.69 & $2.15 *$ & $0.93-4.97$ & I.23 & $0.49-3.09$ \\
\hline
\end{tabular}

Notes: Model I: Associations of disability with wealth. Model 2: Associations of disability with education. Model 3 : Associations of disability with occupational class. Model 4 : Mutually-adjusted associations of disability with wealth, education and occupational class. All models are adjusted for age (in continuous form). OR: odds ratio. CI: confidence interval.

Sources: For the English sample, Wave r of ELSA; for the Greek sample, Wave I of SHARE (for details see text). Significance levels: $* p<0.05, * * p<0.01, * * * p<0.1$.

\section{Multinomial logistic regression results}

Table 4 reports the results obtained using multinomial logistic regression for the ELSA and SHARE samples. Wealth was negatively associated with physical disability in men (Model I), with a much stronger gradient for severe than for mild disability. For example, the English men in the lowest wealth tertile had nearly twice the odds of reporting mild physical disability compared to men in the highest tertile, but nine times the odds of reporting severe physical disability. For the Greek men, the the odds ratios 
were of a similar magnitude (respectively r.6 and 8. I for mild and severe disability). When adjusted for other measures of SEP, the odds were moderately reduced but the gradients of increasing mild and severe disability with decreasing wealth remained clear (Model $4, p<$ o.or).

Education was also negatively associated with physical disability - more strongly for severe than for mild disability in the ELSA sample. For example, compared to men with a high educational level, the odds for men with low education were I.4 times higher for having mild physical disability, and five times higher for severe disability. In the Greek sample, mild disability was not associated with education, but there was a tenuous relationship of severe disability with low education (Model 2). It should be noted that the lack of significant results for the Greeks, particularly with respect to severe disability, may be partly related to the small sample: the directions and magnitudes of the associations are consistent with the ELSA findings. When adjusted for the other two measures of SEP, English men with low education still had statistically significant increased odds of reporting severe disability while the associations with mild disability disappeared. By contrast, in the fully adjusted model, education was no longer associated with disability among Greek men.

The associations with occupational class were the weakest among the three measures of SEP. These associations became non-significant when adjusted for other SEP measures in SHARE. The ELSA respondents with manual occupations had slightly increased odds of severe disability in the fully adjusted model compared to men with managerial professions. The analysis was replicated by selecting the following two more cut-offs for mild and severe disability: mild disability ( $\mathrm{I}_{-}-3$ and $\mathrm{I}^{-} 5$ difficulties) and severe disability $(4+$ and $6+$ difficulties). The associations between SEP and disability did not change with these cut-offs and the results were similar to those we report here for the cut-offs used in this paper.

\section{Predicted probabilities}

To derive more information from the estimated coefficients, predicted probabilities for the three categories of physical disability with wealth, education and occupational status were calculated for the final model and are presented in Figure Ia-c. For all three indicators of SEP, the trends are in the expected direction in all cases, implying that more wealth, higher educational attainment and better occupational status associated with a higher probability of no disability and a lower probability of severe disability. The probabilities for being without disability were generally higher for Greek than English men, while the opposite held for severe disability. For wealth, in particular, the slope of the probabilities was steeper among 


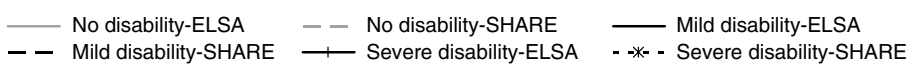

(a) Wealth

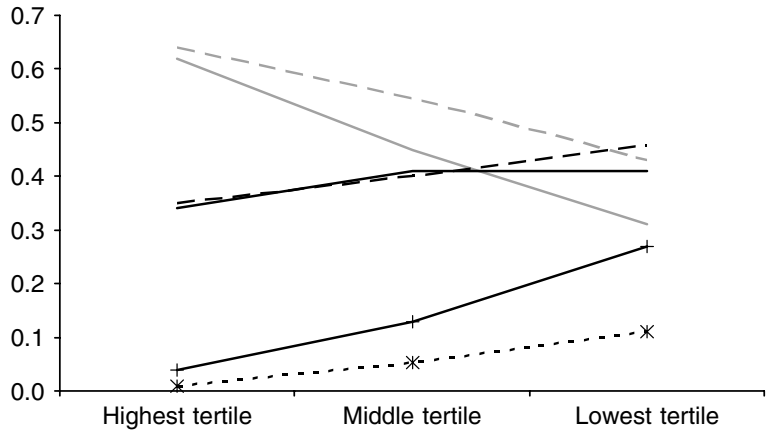

(b) Education

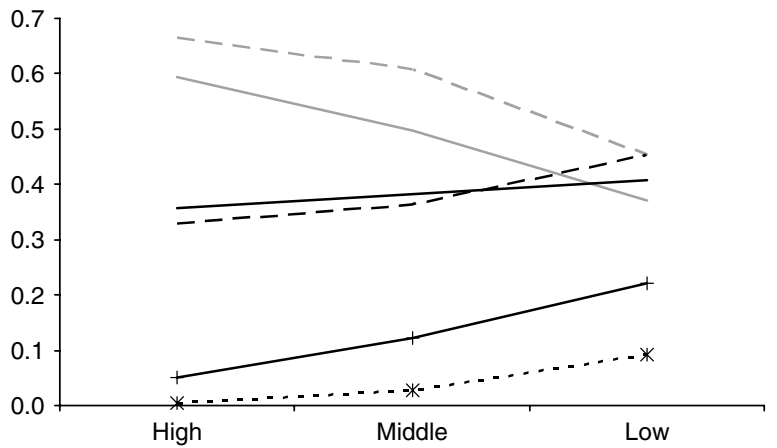

(c) Occupational class

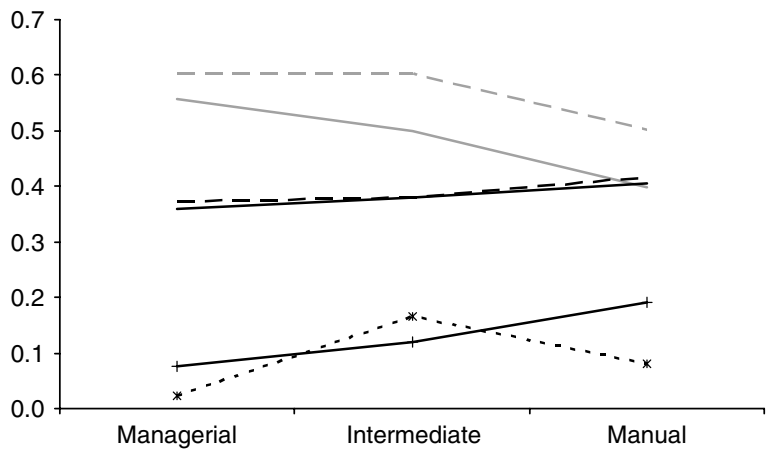

Figure I. Predicted probabilities of severe, mild and no disability by (a) wealth, (b) education and (c) occupational class derived from mutually adjusted associations of disability with wealth, education and occupational class for English and Greek men.

\section{СамвRIDGE JDURALS}


English men, indicating a sharper contrast between poorer and richer men. By contrast, the predicted probabilities for mild disability differentiated very little by SEP, although with tendencies in the expected direction, while they were virtually identical between the English and the Greeks. Comparing the charts in Figure I, the differentials were most pronounced for wealth and least for occupational class. For the Greek sample, severe disability by occupational class showed an inconsistent pattern, no doubt related to the very small numbers (there were only three men with severe disability in the intermediate occupational class).

\section{Discussion}

Our study has demonstrated the existence of socio-economic differentials in physical functioning among older men. The results indicate that among both English and Greek men, there was a strong effect of wealth on disability over and above the effects of education and social class. Moreover, for all three measures, the odds ratios were greater for 'severe' than for 'mild' disability. In the fully adjusted model, education was not associated with disability in Greek men but remained associated with severe disability in English men. For both English and Greek men, occupational class did not strongly associate with disability in the multivariate analyses.

Three measures of individual social position - wealth, educational level and occupational class - were used simultaneously in the model to reduce residual confounding. Of the three, wealth showed the strongest effects on physical functioning over and above the effects of education and social class in both samples. We opted to use wealth instead of income as the latter may be less relevant as a measure of SEP among older people (Costa-Font 2008; Keister and Moller 2000). A strong health-wealth association has been reported previously in Europe (Jurges 2007). There may be different pathways by which wealth affects health. Wealth is an accumulation of assets over the lifecourse, and savings may provide crucial resources when an individual is struck by an unexpected health problem. In contrast, lack of wealth may limit the ability to receive needed care, particularly in countries where access to health care depends heavily upon private payments, as in Greece (Organisation for Economic Cooperation and Development (OECD) 2006). It is also possible that there is an iterative process, by which better health in early life leads to higher SEP, because those with good health are able to participate more in the economic activities and, as a result, accumulate more wealth across their lifecourse, which in turn benefits health in later life. 
Our findings add to the evidence that differences in the prevalence of disability by educational level persist at older ages (Berkman and Gurland I998; Jagger et al. 2007; von dem Knesebeck et al. 2006; Zimmer and House 2003). Moreover, the effects of education on physical functioning remained even when adjusted for wealth and occupational class in English men (but not in Greek men). Our results are in agreement with those from a study of I I European countries and the United States, which showed that education-related inequalities in health are more pronounced in England than Greece (Jurges 2007). Other analyses have found that ADLs among older people in Greece are unrelated to educational level (Tsimbos and Verropoulou 2008). The effects of education on health may reflect those of deprivation early in life on health, or differentials in awareness about access to medical facilities and about healthy eating and healthy lifestyles (Blane 2003). It has been suggested that education relates more strongly to the onset of a functional health problem, while income relates more to its progression - the last might be more dependent on the resources available to provide a healthy environment. Occupational class was not associated with disability in Greek men but there was an association with severe disability in English men, but the relative effect of occupational class compared to wealth and education was weaker. This result supports the thesis that occupational class does not remain an important marker of SEP in old age (Grundy and Holt 200I).

The results of this study are consistent with previous findings that socioeconomic differentials in various health outcomes remain during older age (Berkman and Gurland I998; Breeze et al. 200I; Coppin et al. 2006; Dahl and Birkelund 1997; Ebrahim et al. 2004; Jagger et al. 2007; Minkler et al. 2006; von dem Knesebeck et al. 2006; Zimmer and House 2003). Given the markedly different socio-economic conditions in Greece and England, it is however surprising that the associations between SEP and physical functioning were so similar for Greek and English older men. We know that morbidity patterns and the health-care systems of the two countries differ (Huisman, Kunst and Mackenbach 2003; OECD 2006). According to the OECD report (2006), Greece in 2004 had one of the lowest per capita health expenditures in Europe (excluding eastern Europe) and the lowest share of public spending on health, much lower than in the UK. Comparing patterns in socio-economic inequalities in health among older people in European countries is crucial in designing health policies, especially with respect to those that are promulgated by the European Union which have to balance the heterogeneity of the member countries with the promotion of best practice. Our study fits very well into the existing programme of community health adopted in 
2007, which includes the aim to 'foster healthier ways of life and the reduction of health inequalities' (European Union 2007: 30I/II).

This study adds to the existing knowledge base through its analysis of the relationship between socio-economic status and health, using physical functioning as outcome variable rather than the rates of illness and death. The most fundamental indicators of functional status are difficulties in ADLs, IADLs and mobility. Disability is the final common pathway of many chronic health conditions and reflects not only the presence but also the severity and effect of those conditions. Further, it has been shown that early life events (pre- and post-natal) are important in influencing both development and disease throughout the lifecourse (Barker 1995). Most studies have had one group of disabled people, sometimes at the milder end, sometimes people who are unable to undertake tasks. We have created two groups, the first with few difficulties and the second with many. The disparities in the magnitude of effects of the socio-economic indicators on mild and severe disability found here suggest that those in less advantaged socio-economic positions may be less able to delay the progression of difficulties from a few to many. This argues the importance of keeping health inequalities on the policy agenda. Although our choice for the cut-offs of severe, mild and no disability were arbitrary, the sensitivity analyses performed by using various cut-offs have shown that our results are robust and not influenced by that choice.

The findings are also relevant to the debate about the effects of socioeconomic inequalities on physical functioning in old age. The study has added to the evidence about the relative contribution of various SEP factors among older people and on whether associations are country specific. We were unable to examine the lifecourse impact of SEP on physical functioning in later life due to the nature of the available data. As more information from the successive waves of ELSA and SHARE becomes available, it will be possible to compare transitions from 'no' to 'mild' and to 'severe' disability by SEP. Moreover, having several waves of data will enable the estimation of age-related functions and the closer examination of how socio-economic inequalities alter over time and with age.

A recent study has shown the contribution of SEP factors at various stages across the lifecourse on the onset of physical limitations (Freedman et al. 2008). We have demonstrated for two very different countries that when examining the influence of SEP on physical functioning in old age, wealth is superior to educational attainment and occupational class as the measure. However, education was still found to be significantly associated with severe disability when wealth and occupational class were taken into account, but only for English men. The influence of educational inequalities on physical functioning among English men, and the absence of this 
relationship among Greek men, may be attributable to the countries' different political, educational and occupational traditions (Espelt et al. 2008). Furthermore, the different cultural backgrounds and family support norms in these countries regarding the care of frail older people might account for the different percentages reporting severe disability (Ogg and Renault 2006). Nevertheless, this aspect is beyond the scope of this paper.

The last half century has witnessed a rapid increase in the life expectancy at birth and substantial falls in adult mortality, both in middle life and, more recently, at older ages. A long life expectancy means that elderly people need to spread their economic resources over a longer period. It may also mean that many of them will live the additional years facing chronic health problems and functional dependency. This scenario presents a challenge to policy-makers and posits questions about the quality of life during older ages. Nevertheless, identifying a health-wealth link may provide an incentive to save for later years among both older people and the working-age population. The presented evidence is relevant to the UK government priority programme that aims to reduce health inequalities (Department of Health 2008), although less attention has been paid to inequalities among older groups than among those of working age. This is also a matter of great concern for the Greek government (National Statistical Service of Greece 2002). Nevertheless, comparative research on inequalities among older people is sparse although they represent a growing part of the population who may be particularly vulnerable to poor functioning by virtue of poor environment and worsening health. Improved understanding about the contribution of various SEP factors to their wellbeing is of primary importance and has evident policy implications.

We believe that this is the first study to investigate the relative importance of various SEP factors with respect to physical functioning in two distinct national populations. Moreover, the analysis has differentiated people with 'mild' and 'severe' disability rather than treating all with disabilities as a homogeneous group. The study also has a number of limitations. First, given the cross-sectional data, we were unable to examine changes in disability over time. In addition, causality may be ambiguous, particularly with respect to last occupation and wealth, since ill-health itself may have caused downward mobility and a reduction in net wealth. Second, ELSA and SHARE did not include people living in institutions and, as a result, a group with high rates of morbidity has been omitted from the analysis. This exclusion might have led to under-estimates of socio-economic differentials in health. Finally, the data on ADL, IADL and mobility limitations are based on self-reports. Our analysis is therefore 
based on assumptions that the reporting was reliable and there was no systematic bias by SEP among either the English or the Greeks.

\section{Conclusions}

Socio-economic factors have an impact on physical functioning for both English and Greek men, two quite distinct European populations. The findings also indicate that wealth has the strongest effect as compared to both educational level and occupational class, while the magnitude of the effect is more substantial for severe than mild disability. Greater educational inequalities were found among English men as compared to the Greeks. The dominance of wealth over the other measures suggests that interventions early in the lifecourse to promote opportunities for a healthy lifestyle and the accumulation of resources may be beneficial, but that does not rule out that more affordable care and environmental changes could make important differences in later life. Improved understanding about the contribution of various SEP factors to the wellbeing of older populations will have important policy implications.

\section{Acknowledgements}

ELSA is co-funded by the United States National Institute on Aging and by UK Government departments involved in areas relating to the ageing process. The data were made available throug the UK Data Archive. The funders supported the ELSA study but played no other role in the preparation or submission of this manuscript. The SHARE data collection has been primarily funded by the European Commission through the Fifth Framework Programme. Data collection in Austria, Belgium and Switzerland was nationally funded while in Israel it was funded by the United States National Institute on Aging. Further support by the European Commission through the Sixth Framework Programme is gratefully acknowledged.

\section{NOTES}

I Although the International Classification of Functioning, Disability and Health (ICF) framework includes refined measurements of disability (World Health Organization 200I), the measures used in this paper are still valid.

2 The technical details and the primary analyses of the Wave I data have been published (Banks et al. 2006). Ethical approval for the data collection was obtained from the London Multi Research Ethics Committee (reference or/2/9I).

3 The technical details and a preliminary analysis are provided elsewhere (BörschSupan and Jürges 2005; Börsch-Supan et al. 2005).

4 Ordinal regression, which might be appropriate as the dependent variable is ordered, was rejected on the grounds that the main diagnostic failed (namely test of parallel regression). The analyses were carried out using STATA 9.2 (StataCorp 2005). 


\section{References}

Agresti, A. 2002. Categorical Data Analysis. Wiley, New York.

Artazcoz, L. and Rueda, S. 2007. Social inequalities in health among the elderly: a challenge for public health research. Journal of Epidemiology and Community Health, 6r, 6, 466-7.

Banks, J., Breeze, E., Lessof, C. and Nazroo, J. 2006. Retirement, Health and Relationships of the Older Population in England: The 2004 English Longitudinal Study of Ageing (Wave 2). Institute of Fiscal Studies, London.

Banks, J., Emmerson, C. and Tetlow, G. 2005. Estimating Pension Wealth of ELSA Respondents. Institute of Fiscal Studies, London.

Barker, D. J. I995. Fetal origins of coronary heart disease. British Medical fournal, 3 I I, 6998, I $7 \mathrm{I}-4$.

Berkman, C. S. and Gurland, B. J. 1998. The relationship among income, other socioeconomic indicators, and functional level in older persons. Fournal of Aging and Health, го, I, 8I-98.

Bhattacharya, J., Choudhry, K. and Lakdawalla, D. 2008. Chronic disease and severe disability among working-age populations. Medical Care, 46, I, 92--1oo.

Blane, D. 2003. Explanations of the difference in mortality risk between different educational groups. International fournal of Epidemiology, 32, 3, 355-6.

Blane, D., Netuveli, G. and Montgomery, S. M. 2008. Quality of life, health and physiological status and change at older ages. Social Science and Medicine, 66, 7, I579-87.

Börsch-Supan, A., Brugiavini, A., Jürges, H., Mackenbach, J. P., Siegrist, J. and Weber, G. (eds) 2005. Health, Ageing and Retirement in Europe: First Results from the Survey of Health, Ageing and Retirement in Europe. Research Institute for the Economics of Ageing, Mannheim, Germany.

Börsch-Supan, A. and Jürges, H. 2005. The Survey of Health, Ageing and Retirement in Europe: Methodology. Research Institute for the Economics of Ageing, Mannheim, Germany.

Breeze, E., Fletcher, A. E., Leon, D. A., Marmot, M. G., Clarke, R. J. and Shipley, M. J. 200I. Do socioeconomic disadvantages persist into old age? Self-reported morbidity in a 29-year follow-up of the Whitehall Study. American Fournal of Public Health, 9, 2, $277-83$.

Coppin, A. K., Ferrucci, L., Lauretani, F., Phillips, C., Chang, M., Bandinelli, S. and Guralnik, J. M. 2006. Low socioeconomic status and disability in old age: evidence from the Inchianti study for the mediating role of physiological impairments. Fournals of Gerontology: Biological Sciences and Medical Sciences, 6r i, I, 86-9I.

Costa-Font, J. 2008. Housing assets and the socio-economic determinants of health and disability in old age. Health and Place, 14, 3, 478-9I.

Dahl, E. and Birkelund, G. E. I997. Health inequalities in later life in a social democratic welfare state. Social Science and Medicine, 44, 6, 87I-8I.

Department of Health 2008. Tackling Health Inequalities: 2007 Status Report on the Programme for Action. Department of Health, London.

Ebrahim, S., Papacosta, O., Wannamethee, G. and Adamson, J. 2004. Social inequalities and disability in older men: prospective findings from the British regional heart study. Social Science and Medicine, 59, I0, 2109-20.

Eikemo, T. A., Huisman, M., Bambra, C. and Kunst, A. E. 2008. Health inequalities according to educational level in different welfare regimes: a comparison of 23 European countries. Sociology of Health and Illness, 30, 4, 565-82.

Elias, P. and Birch, M. 1994. Establishment of Community-wide Occupational Statistics: A Guide for Users. Report ISCO 88 (COM). Institute for Employment Research, University of Warwick, Coventry, UK. 
Espelt, A., Borrell, C., Rodriguez-Sanz, M., Muntaner, C., Pasarin, M. I., Benach, J., Schaap, M., Kunst, A. E. and Navarro, V. 2008. Inequalities in health by social class dimensions in European countries of different political traditions. International fournal of Epidemiology, 37, 5, 1095-105.

European Union 2007. Decision 1350/2007/EC of the European Parliament and of the Council of 23 October 2007 Establishing a Second Programme of Community Action in the Field of Health (2008-I3). Official Fournal of the European Union, 20 November, L 301/3. Available online at http://eur-lex.europa.eu/LexUriServ/LexUriServ.do?uri=OJ:L:2007:301:0003:0013: EN:PDF [Accessed 28 November 2008].

Fonda, S. and Herzog, A. 2004. Documentation of Physical Functioning Measured in the Health and Retirement Study and the Asset and Health Dynamics Among the Oldest Old Study. HRS/AHEAD Documentation Report. Institute of Social Research, University of Michigan, Ann Arbor, Michigan. Available online at http://hrsonline.isr.umich.edu/docs/sho_ refs.php?hfyle $=$ index\&xtyp $=3$ [Accessed i3 February 2009].

Freedman, V. A., Martin, L. G., Schoeni, R. F. and Cornman, J. C. 2008. Declines in latelife disability: the role of early- and mid-life factors. Social Science and Medicine, 66, 7, I588-602.

Grundy, E. and Holt, G. 200I. The socioeconomic status of older adults: how should we measure it in studies of health inequalities? Fournal of Epidemiology and Community Health, 55, I2, 895-904.

Huisman, M., Kunst, A. E. and Mackenbach, J. P. 2003. Socioeconomic inequalities in morbidity among the elderly: a European overview. Social Science and Medicine, 57, 5, $86 \mathrm{I}-73$.

Hyde, M. and Jones, I. R. 2007. The long shadow of work: does time since labour market exit affect the association between socioeconomic position and health in a post-working population? Fournal of Epidemiology and Community Health, 6 I, 6, 533-9.

Jagger, C., Matthews, R., Melzer, D., Matthews, F., Brayne, C. and MRC CFAS. 2007. Educational differences in the dynamics of disability incidence, recovery and mortality: findings from the MRC Cognitive Function and Ageing Study (MRC CFAS). International Fournal of Epidemiology, 36, 2, 358-65.

Jurges, H. 2007. Health Inequalities by Education, Income and Wealth: A Comparison of II European Countries and the US. Research Institute for the Economics of Aging, University of Mannheim, Germany.

Katz, S., Ford, A. B., Moskowitz, R. W., Jackson, B. A. and Jaffe, M. W. Ig63. Studies of illness in the aged. The index of ADL: a standardised measure of biological and psychological function. Fournal of the American Medical Association, 185, 914-9.

Keister, L. A. and Moller, S. 200o. Wealth inequalities in the United States. Annual Review of Sociology, 26, I, 63-8I.

Lamarca, R., Ferrer, M. Andersen, P. K., Liestol, K., Keiding, N. and Alonso, J. 2003. A changing relationship between disability and survival in the elderly population: differences by age. Fournal of Clinical Epidemiology, 56, I2, I I92-201.

Launer, L. J., Harris, T., Rumpel, C. and Madans, J. I994. Body mass index, weight change and risk of mobility disability in middle-aged and older women: the epidemiologic follow-up study of NHANES I. Fournal of the American Medical Association, 271, I4, I093-8.

Lawton, M. P. and Brody, E. M. i969. Assessment of older people: self-maintaining and instrumental activities of daily living. The Gerontologist, 9, 3, I79-86.

Mackenbach, J. P. and Bakker, M. J. 2003. Tackling socioeconomic inequalities in health: analysis of European experiences. The Lancet, 362, 9393, I409-14.

Mackenbach, J. P. and Kunst, A. E. I997. Measuring the magnitude of socio-economic inequalities in health: an overview of available measures illustrated with two examples from Europe. Social Science and Medicine, 44, 6, 757-71. 
Mackenbach, J. P., Kunst, A. E., Cavelaars, A. E., Groenhof, F. and Geurts, J. J. I997. Socioeconomic inequalities in morbidity and mortality in western Europe. The Lancet, 349, 9066, I655-9.

Minkler, M., Fuller-Thomson, E. and Guralnik, J. M. 2006. Gradient of disability across the socioeconomic spectrum in the United States. New England Fournal of Medicine, 355, 7, 695-703.

National Statistical Service of Greece 2002. National Survey of Persons with Health or Disability Problems. National Statistical Service of Greece, Athens.

Office of National Statistics 2005. The National Statistics Socio-economic Classification User Manual. Office of National Statistics, London.

Ogg, J. and Renault, S. 2006. The support of parents in old age by those born during I945-I954: a European perspective. Ageing \& Society, 26, 5, 723-43.

Olsen, K. M. and Dahl, S. 2007. Health differences between European countries. Social Science and Medicine, 64, 8, I665-78.

Organisation for Economic Cooperation and Development (OECD) 2006. OECD Health Data 2006: How Does Greece Compare? OECD, Paris.

Scott, W. K., Macera, C. A., Cornman, C. B. and Sharpe, P. A. 1997. Functional health status as a predictor of mortality in men and women over 65. Fournal of Clinical Epidemiology, 5o, 3, 29I-6.

StataCorp. 2005. Stata Manual: Release 9. Stata Press, College Station, Texas.

Tsimbos, C. and Verropoulou, G. 2008. A multivariate analysis of factors associated with physical functioning limitations in the Greek elderly population. Fournal of Statistics and Management Systems, I I , 6, гі6 $1-80$.

United Nations Development Programme 2006. Human Development Report 20o6. Beyond Scarcity: Power, Poverty and Global Water Crisis. Palgrave Macmillan, New York.

United Nations Educational Scientific and Cultural Organisation (UNESCO) 2006. International Standard Classification of Education 1997. Re-edition, UIS/TD/o6-or, UNESCO, Paris, 2006.

von dem Knesebeck, O., Verde, P. E. and Dragano, N. 2006. Education and health in 22 European countries. Social Science and Medicine, 63, 5, I344-5I.

Wilkie, R., Peat, G., Thomas, E. and Croft, P. 2007. Factors associated with participation restriction in community-dwelling adults aged 50 years and over. Quality of Life Research, I6, 7, II $47^{-5}$.

Winkleby, M. A., Jatulis, D. E., Frank, E. and Fortmann, S. P. I992. Socioeconomic status and health: how education, income and occupation contribute to risk factors for cardiovascular disease. American Fournal of Public Health, 82, 6, 816-20.

World Health Organization 200r. International Classification of Functioning, Disability and Health. World Health Organization, Geneva.

Zimmer, Z. and House, J. S. 2003. Education, income and functional limitation transitions among American adults: contrasting onset and progression. International fournal of Epidemiology, 32, 6, 1089-97.

Address for correspondence:

Accepted 6 March 2009; first published online I8 Fune 2009

Faiza Tabassum, Epidemiology and Public Health, University College

London, I-I9 Torrington Place, London WGiE 6BT, UK.

E-mail: f.tabassum@ucl.ac.uk 